\title{
Cerebrovascular Neurosurgery in Canada: An Historical Review
}

\author{
Suresh Ramnath
}

ABSTRACT: Canadian contributions to cerebrovascular neurosurgery have been disproportionately large and, with some exceptions, relatively unrecognized. In this review, some of the efforts in the advancement of cerebrovascular neurosurgery by Canadian neurologists and neurosurgeons are described.

RÉSUMÉ: La neurochirurgie cérébro-vasculaire au Canada : une revue historique. Les contributions canadiennes à la neurochirurgie cérébrovasculaire ont été très importantes et, à quelques exceptions près, relativement méconnues. Dans cette revue, nous décrivons quelques-unes des initiatives de neurologues et de neurochirurgiens canadiens qui ont contribué à l'avancement de la neurochirurgie cérébro-vasculaire.

Keywords: Canada, cerebrovascular, historical, neurosurgery

doi:10.1017/cjn.2017.276

Can J Neurol Sci. 2018; 45: 227-234

Early Canadian interest in vascular disorders of the brain was first demonstrated by William Osler (1849-1919; Figure 1A). Born in Bond Head near Toronto, Dr. Osler obtained his MD degree at McGill University in 1872 . He was appointed to a post in medicine and pathology there in 1873 . In 1886, he wrote on intracranial aneurysms ${ }^{1}$ based on a series of approximately 1,000 autopsies (1875-1885). An unpublished sketch found in 1928 by W.W. Francis showed 10 aneurysms - two of the basilar trunk and the remainder in the anterior circulation (Figure 1B). ${ }^{2}$ In an editorial in $1889,{ }^{3}$ Osler considered intracranial hemorrhages as "suitable for operative interference," as well as abscesses and neoplasms. William Lougheed, writing in Youmans's textbook, ${ }^{4}$ praised Osler's accurate postmortem description of an intracerebral hematoma from a ruptured middle cerebral artery aneurysm. ${ }^{5}$ Osler recognized transient ischemic attacks - such as episodic aphasia, paralysis, and visual disturbances 6 _including that of his friend, Dr. George Ross, mentioned in his 1892 textbook. In 1874, Osler was possibly the first to recognize platelets as a distinct component of blood and that they aggregated in shed blood together with strands of fibrin, but he did not elucidate their origin or role in cerebrovascular disease. ${ }^{7,8}$ In his textbook, he wrote about cerebral arterial occlusions but felt they were of embolic origin, rather than thrombotic, and described cerebral venous sinus thrombosis.

Later, as professor of medicine at Johns Hopkins, Osler met and influenced Harvey Cushing, then a surgical resident under William Halsted, professor of surgery. Osler, more than Halsted, encouraged Cushing's pursuit of neurosurgery, and indirectly that of Walter Dandy and later Wilder Penfield. Cushing wrote the chapter on "Diseases of the Nervous System" for the sixth edition of Osler's textbook The Principles and Practice of Medicine, and also a Pulitzer Prize-winning biography of Osler in 1925.

Operative treatment at that time was by Hunterian ligation of the cervical carotid arteries. The first to clip the neck of a posterior communicating aneurysm was Walter Dandy in Baltimore in 1937, using a McKenzie "silver clip."

Kenneth McKenzie (1892-1964, born in Monkton, Ontario, MD Toronto, 1914, son of a physician) was the first "dedicated" neurosurgeon in Canada. After serving in World War I, then working three years in general practice and general surgery, he obtained a fellowship with Cushing in Boston in 1923-1924. He returned to Toronto and modified the Cushing silver clip in $1927 .{ }^{9}$ He devised an instrument to punch out a uniformly V-shaped clip from a flat wire, and special clip holders to apply them. This was in contrast to the U-shaped Cushing clip. McKenzie claimed that the Cushing clip could close at the tips, but not reliably or completely at its proximal part, and possibly did not totally occlude the vessel. He felt that the V-shaped clip was more likely to accomplish this. McKenzie's V-shaped clip was the forerunner of the present day hemostatic vascular clip. While used to control bleeding from vessels in general, it is not known if these had been used for cerebral aneurysms until Dandy's report in $1944 .^{9,10}$ The Olivecrona clip was a modification of McKenzie's clip, adding proximal wings to the blades and permitting opening of the clip for readjustment. Charles Drake mentions that both McKenzie in Toronto and William V. Cone in Montreal (born 1897 in Iowa, MD Iowa, 1922, associated with Wilder G. Penfield as cofounder of the Montreal Neurologic Institute 1934) had excised aneurysms, as reported in 1938 at the annual meeting of the Harvey Cushing Society. ${ }^{11}$ Cone's experience was probably an

From the Department of Neurosurgery, University of Michigan, Ann Arbor, Michigan.

Received November 28, 2016. Final Revisions Submitted July 18, 2017. Date of ACCEPTANCE SEPTEMBER 13, 2017.

Correspondence to: Suresh Ramnath, Department of Neurosurgery, University of Michigan, 1500 East Medical Center Drive, Room 3552 TC, Ann Arbor, Michigan 48109-5338. Email: ramnaths@med.umich.edu 

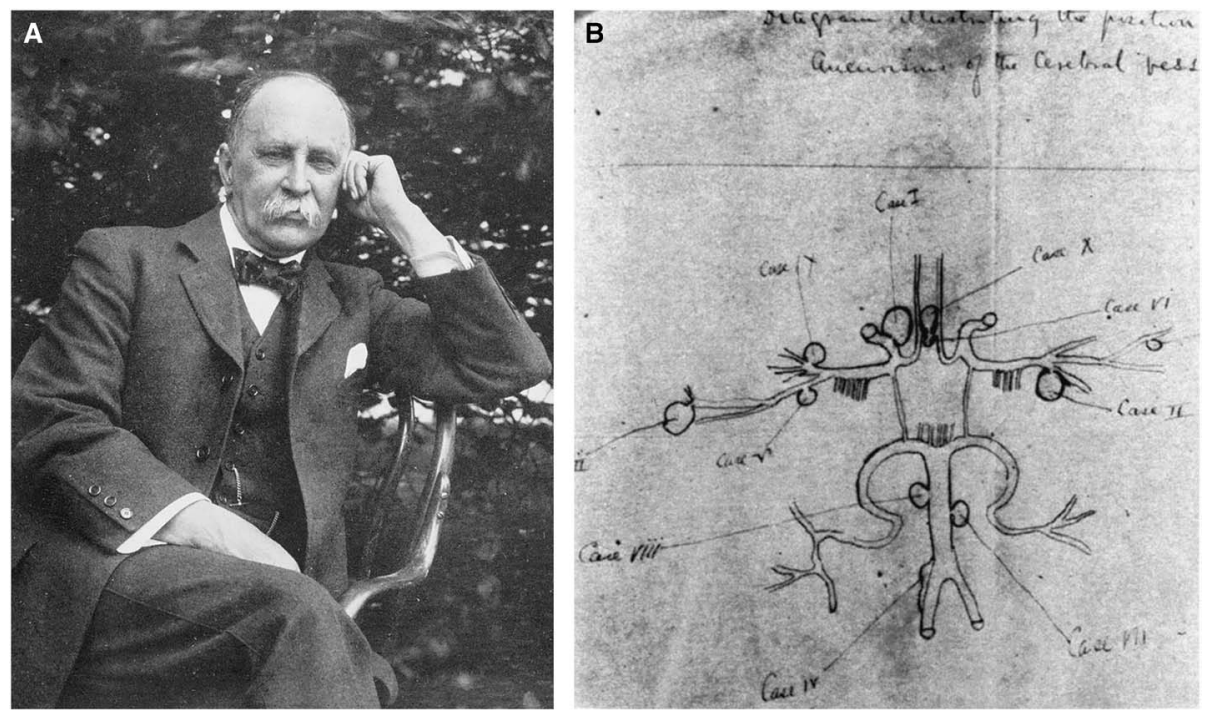

Figure 1: (A) Photograph of Dr. William Osler, circa 1912. Reproduced from Wikimedia Commons. (B) Osler's complete sketch of cerebral artery aneurysms. Reproduced with permission from Can J Neurol Sci. 2000;254:255.

anterior communicating aneurysm. ${ }^{12}$ Until retirement in 1952 , McKenzie's career in Toronto firmly established neurosurgery as a specialty in Canada. He began the first neurosurgical residency program in Canada and trained Frank Turnbull, Harry Botterell, William Lougheed, and Charles Drake, among others. McKenzie was president of the Cushing Society in 1936-1937 and also of the "Senior" Society of Neurological Surgeons in 1948-1949. During the 1940s and 1950s, surgical treatment of the cervical and cranial vasculature made steady progress. McKenzie apparently said that aneurysm surgery was a game for younger surgeons, and he then left it to his juniors in Toronto to pursue. ${ }^{11}$

Interest in the planned surgical treatment of vascular diseases of the brain increased after the introduction of angiography by Egas Moniz in 1927, exposing the cervical carotid artery directly. Frank Turnbull (1904-2000, MD Toronto, 1928) reported on percutaneous carotid angiography in $1939,{ }^{13}$ three years after Loman and Myerson. Turnbull, the first neurosurgeon to practice in Western Canada (Vancouver), was president of the Harvey Cushing Society in 1949-1950.

E. Harry Botterell (1906-1997, born in Vancouver, MD Manitoba, 1930) began training in Winnipeg and Montreal and went to Toronto in 1932, teaching physiology under Charles H. Best (honored with Nobel Prize winners Frederick Banting and John McLeod for the discovery of insulin in 1923; in the 1930s, Best also pioneered in the isolation and clinical use of heparin), and anatomy under J. C. Boileau Grant (of the Atlas of Anatomy). He became a resident under W.E. Gallie (who described a technique for C1-C2 fusion) and between 1934 and 1935 was a house physician at Queen's Square in London, England. From 1935 to 1936, Botterell did a research fellowship in neurophysiology at Yale under Dr. John Fulton and worked with A. Earl Walker (1907-1995, born in Winnipeg, MD Alberta, 1930, later professor of neurosurgery at Johns Hopkins; known for the Dandy-Walker and Walker-Warburg syndromes) and D. Denny Brown on cerebral and cerebellar physiology. He returned to Toronto in 1936 to work with McKenzie. Botterell served with the Royal Canadian Army during World War II. He visited Sir Geoffrey Jefferson in Manchester and was likely influenced by Jefferson's views on intracranial aneurysms. He succeeded McKenzie as head of the section in 1952. There had been a few planned aneurysm operations under McKenzie, but their number increased greatly during Botterell's tenure.

In a landmark paper in $1956{ }^{14}$ and again in $1958,{ }^{15}$ Botterell and his associates W.M. Lougheed and T.P. Morley described the first practical gradation of subarachnoid hemorrhage and discussed its relationship to surgical outcome. The Botterell scale consisted of five grades. In addition, these were the world's first reports of hypothermia, hypotension, and intermittent interruption of the carotid and/or vertebral arteries to improve the results of aneurysm surgery. They also discussed the timing of surgical intervention (early, preferably within a week), the effect of the size and site of the aneurysm, patient age, and the presence of massive intracranial bleeding. Hypothermia to $30^{\circ} \mathrm{C}$ by external cooling together with a "lytic cocktail" (meperidine, promethazine, and chlorpromazine) was used without cardiac arrest. They recognized that hypothermia did not eliminate vasospasm but provided major protection from anoxia. Their results also reflected an early "outcome score." Their experience with this technique began in May of 1954, based on the work of Wilfred Bigelow, a cardiac surgeon at the Toronto General Hospital.

The Hunt and Hess scale (1968), based on 12 years of experience, made further minor modifications, including a grade 0 for an asymptomatic aneurysm. The major prognostic value of the Hunt and Hess scale was that the grading was done just before the operation rather than at the time of presentation. The Hunt and Hess scale gave proper attribution to the Botterell scale, with only minor additions, but surprisingly has relegated the Botterell scale to obscurity.

William M. Lougheed (1923-2004, born at Toronto General Hospital, son of a physician practicing in Toronto; MD Toronto, 1947; Figure 2A) began training at the Toronto General Hospital with cardiac surgeons Gordon Murray and Wilfred Bigelow, but he fell under the spell of neurological surgery and learned the craft from McKenzie and Botterell. ${ }^{16}$ It was Bigelow's investigations into cardiac surgical procedures using hypothermia that intrigued Lougheed about cerebral operations using reversible arrest of 

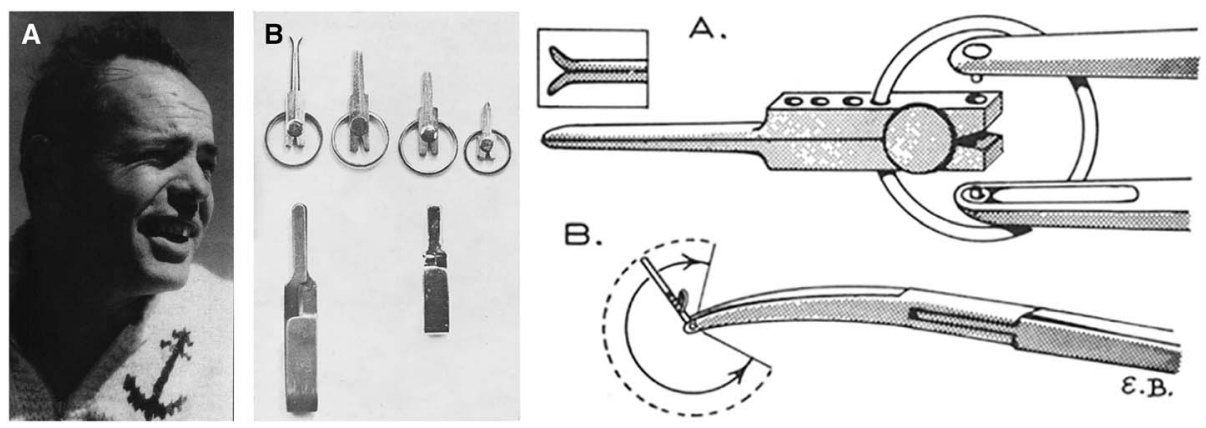

Figure 2: (A) Photograph of Dr. William M. Lougheed, circa 1960. Reproduced with permission from Findlay JM. ${ }^{16}(B)$ Left: Lougheed clip, as designed by Mr. Harry S. Kerr, in several sizes (top row), with the Schwartz clip (lower left) and Mayfield clip (lower right). Right: Drawing of (A) tip of clip holder and the clip; $(B)$ angular rotation of the clip and bifurcated ski-board tips. Reproduced with permission from Lougheed and Khodadad. ${ }^{31}$

circulation and hypothermia. He spent two years in Boston with Dr. William Sweet studying cerebral responses to anoxia under hypothermia. ${ }^{17}$ They found that the dog brain could tolerate cerebral anoxia and a reduced metabolic rate at temperatures of $25^{\circ} \mathrm{C}$ for as long as 22 minutes of circulatory arrest. Systemic hypothermia was preferred to cooling only the brain. In 1955, with Drs. Sweet, White, and Brewster, he reported the first two neurosurgical patients ever to be operated on under hypothermia. ${ }^{18}$ The first was a hemispherectomy for recurrent glioblastoma with temporary occlusion of both common carotid arteries, and the other was for a large arteriovenous malformation, with bilateral carotid and vertebral occlusion. The laboratory and clinical experience then led to the use of these adjuncts in operating on intracranial aneurysms with Botterell after his return to Toronto in 1954. While they showed that complex aneurysms could be operated on with greater facility, outcomes were not necessarily optimal. They also did not provide definitive evidence as to timing of operations, although they preferred early operation based on the Botterell scale. During Lougheed's stay in Boston in 1953, he assisted Drs. Hamlin and Sweet in operations to reopen occluded or stenosed cervical carotid arteries by end-to-end anastomosis. ${ }^{19}$ The better-known reports of Eastcott, Pickering, and Robb (possibly influenced by C.P. Symonds' knowledge of the investigations of C.M. Fisher), Cooley, DeBakey, and others spurred the expansion of carotid surgery in the 1950s.

Lougheed amassed a large series of carotid endarterectomies (over a thousand). He established a research laboratory at the Banting Institute and with Dr. Mary I. Tom (neuropathologist at Toronto General Hospital) starting in the mid-1950s, devised a model of subarachnoid hemorrhage by transpalatal injection of blood through a burr hole into the basal cisterns of a dog using a dissecting microscope ${ }^{20}$ Because of difficulty using the operating microscopes of those times (a Zeiss OpMi-1) that had a binocular eyepiece for the operating surgeon but only a monocular eyepiece on a sidebar for the assistant, Lougheed was instrumental in the development of a more maneuverable split-beam "diploscope" by Zeiss, which allowed binocular vision for the assistant directly across from the operating surgeon, making assistance more effective. ${ }^{21} \mathrm{He}$ was Canada's first neurosurgeon to utilize the microscope extensively, and among the world's first microneurosurgeons. He pioneered microsurgical techniques and was in frequent contact with Dr. R.M.P. Donaghy in Burlington, Vermont. Together with G. Khodadad, Lougheed reported on their laboratory experiences in microvascular reconstruction, using contact cement, Teflon grafts, suture and stapling techniques, as well as non-suture anastomosis. ${ }^{22-24}$ The non-suture technique consisted of threading the vessels to be anastomosed end-to-end through a cylinder and ring-shaped clip, allowing for intima-tointima contact without a foreign body in the lumen. ${ }^{25} \mathrm{~A}$ modification of this device also allowed for end-to-side anastomosis. Although many hundreds of these procedures were performed on animal models and on human cadaver vessels, they did not replace microvascular suture anastomosis. Based on this expertise, and on reports of previous middle cerebral artery embolectomy (see Jacobson et al., ${ }^{26}$ Chou, ${ }^{27}$ and Scheibert ${ }^{28}$ ), Lougheed reported in 1965 the successful removal of an embolus in the internal carotid artery bifurcation extending into the proximal anterior and middle cerebral arteries. ${ }^{29}$ In 1971, he reported the first successful saphenous vein graft from the common carotid to the supra-cavernous internal carotid artery in a woman with a completely occluded cervical internal carotid. ${ }^{30} \mathrm{He}$ had failed on two previous attempts because of extensive atherosclerosis in the intracranial internal carotid.

Lougheed found that the aneurysm clips available in the early 1960s were not always of the variety, length, and shape he desired. Therefore, with Harry S. Kerr, a Toronto jeweler, he devised a smaller clip with a proximal C-shaped spring inserted into indentations in the hub, allowing rotation of the clip to different angles, and the ability to adjust blade tension by altering the position of the $\mathrm{C}$-spring on the hub (Figure 2B) ${ }^{31} \mathrm{He}$ was among the first to use temporary proximal artery occlusion to assist in clipping aneurysms, and was a proponent of early operation (within 24 hours) in patients with good scores.

Dwight Parkinson (1916-2005, born in Idaho, MD McGill, 1941) trained at the Mayo Clinic (Rochester, Minnesota) and began his career at the University of Manitoba in Winnipeg in 1950. Parkinson contributed to the anatomy and treatment of carotid-cavernous fistulae. He published the results of cadaveric dissections of the carotid artery and its branches in the cavernous sinus. ${ }^{32} \mathrm{He}$ asserted that the cavernous sinus was not a simple endothelium-lined cavity like other intracranial venous sinuses, as commonly believed, but a space (lateral sellar compartment) containing a "parasellar venous plexus" encapsulated in dura, which the carotid artery with its periadventitial sympathetic plexus and abducent nerve traversed in association with the oculomotor, trochlear, trigeminal nerves (ophthalmic division), in the roof and lateral wall (illustrations in Pernkopf's atlas dating 
back to 1954 had indeed shown a venous plexus surrounding the carotid artery).

He also laid to rest the traditional teaching that there were no branches of the internal carotid artery until it emerged from the cavernous sinus. In 1964, after failure of conventional treatments of traumatic fistula, he directly approached the cavernous carotid artery to obliterate the arteriovenous connection and preserved patency of the internal carotid, under hypothermia and cardiac arrest. ${ }^{33}$ The approach was through "Parkinson's triangle" in the lateral wall of the cavernous sinus. This was the first reported direct approach into the cavernous sinus and pointed the way for later attacks on intracavernous neoplasms and aneurysms. For the obliteration of arteriovenous malformations, Parkinson developed simultaneous biplane stereoscopic angiography, including its intraoperative use. ${ }^{34} \mathrm{He}$ emphasized clipping the feeding vessels and the draining veins as close to the "fistula" as possible, and excising the malformation completely to prevent recurrent bleeds. ${ }^{35} \mathrm{He}$ described the arterial appearance of the draining veins before general usage of the term "red veins." He commented on the futility of deep X-ray therapy to obliterate these malformations. According to Yasargil, ${ }^{36}$ Parkinson had used an operating microscope in the laboratory in the late 1950s.

Charles G. Drake (1920-1998, born in Windsor, Ontario, MD Western Ontario, 1944) received his training with McKenzie and Botterell, straying from an initial interest in internal medicine. In 1949, as McKenzie's resident, he drained an intracerebral hematoma to clip a middle cerebral branch aneurysm on one of Botterell's patients, following repeated bleeds. In 1951, as a resident, he published a short note on the use of a polyethylene tube attached to the needle for percutaneous carotid angiography, in order to stabilize the needle during contrast injection. Following Drake's residency, McKenzie arranged for him to visit Jefferson (Manchester), Dott (Edinburgh), Hugh Cairns (Oxford), and Herbert Olivecrona (Stockholm). He conducted research on the "primunculus" in the anterior cerebellum with John Fulton at Yale. McKenzie encouraged Drake to start a neurosurgical service at the University of Western Ontario in London. In early 1959, after cadaveric dissections and with McKenzie's blessing, he successfully clipped a basilar bifurcation aneurysm. ${ }^{37}$ In later discussions on the treatment of giant intracranial aneurysms, ${ }^{38}$ Drake described the use of his tourniquet for graduated occlusion of the neck of the aneurysm or the main trunk bearing the aneurysmal sac (Figure 3A). This consisted of a 3-0 polypropylene suture threaded through a fine polyethylene tube brought to the scalp through a separate stab incision. A small clip at the end of the tube marked the position of the distal tube, and after a trial occlusion, the proximal end was buried under the scalp or fascia with another small clip. Because of inadvertent inclusion of vessels in the immediate proximity of the aneurysmal neck, he devised a fenestrated clip (Drake-Kees, modified Mayfield clip) in 1969, which allowed sparing these vessels (Figure 3B). This also allowed him to clip wide-necked aneurysms in tandem fashion. In Del Maestro's account, ${ }^{39}$ Drake had been contemplating how to clip a basilar bifurcation aneurysm in a patient referred by J.L. Poole of New York. After damaging several Mayfield clips in vitro, he telephoned Frank Mayfield in Cincinnati about creating an aperture in the proximal part of the clip to accommodate the posterior cerebral artery. A few days later, three fenestrated clips of varying length fabricated by George Kees Jr. arrived, allowing Drake to successfully clip the aneurysm. Kenichiro Sugita, after
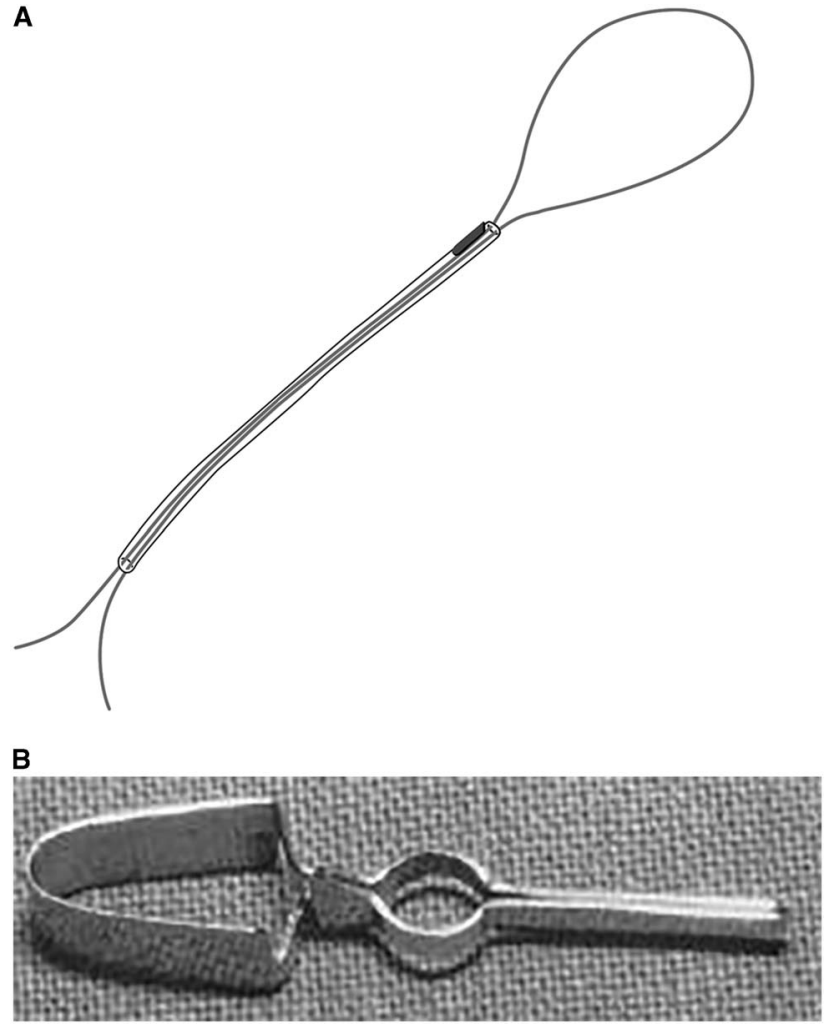

Figure 3: (A) Artist's rendering of Drake's tourniquet (by M. Foldenauer). (B) Photograph of Drake fenestrated clip, also referred to as modified Mayfield clip. Reproduced with permission from Drake CG. Management of aneurysms of posterior circulation. In: Youmans JR (ed.), Neurological Surgery, Vol. 2. Philadelphia: W.B. Saunders, 1973: 792.

Drake demonstrated these clips to him, was able to modify them further in Japan. These clips were subsequently used on aneurysms in various other locations, preserving arteries and nerves in the fenestration.

Dr. Drake was the chairman of a group of six internationally recognized neurosurgeons who established the World Federation of Neurological Surgeons Subarachnoid Hemorrhage Scale in 1988. It was a blend of the previous scales of Botterell, Hunt and Hess, the Glasgow Coma Score (1974), and the Glasgow Outcome Scale (1975). It was intended to be simple, reliable, and designed to estimate patient prognosis, evaluate treatment by various techniques, and quantify neurologic status between bleed, preoperative, and postoperative periods. ${ }^{40}$

Drake also utilized extracorporeal circulation and profound hypothermia to operate on aneurysms. ${ }^{41}$ Initial experience with deep hypothermia $\left(15^{\circ} \mathrm{C}\right)$ and cardiac arrest did not prevent bleeding from the brain, and they were later abandoned for profound hypotension and delayed operation. He stated that the advantages of operating on a soft aneurysm in a dry field with a slack brain prevented many complications. Drake early recognized the need for follow-up arteriography, and together with neuroradiologist J.M. Allcock began to routinely evaluate the degree of postoperative occlusion of the neck and sac of aneurysms and patency of vessels in their proximity. ${ }^{42}$ This also provided further exploration and study of arterial spasm. ${ }^{43}$ In their paper of $1965,{ }^{43}$ they stated that it might be reasonable to try to 
maintain blood pressure at or above the patient's normal range after clipping, to alleviate the effects of vasospasm. Although in 1951 A.E. Ecker and P.A. Riemenschneider had described arterial spasm as a result of subarachnoid hemorrhage, ${ }^{44}$ little had been written since. Drake's contacts as a resident with J. Richardson and H. Hyland, ${ }^{45}$ neurologists at Toronto General Hospital who were interested in subarachnoid bleeding (but more in medical management than in surgical intervention), later marked his association with neurologist Henry Barnett in establishing a combined neurosciences unit at the University of Western Ontario. Drake's juniors-Gary Ferguson (1941-2011, MD Western Ontario, 1965) and Sidney Peerless (1936-, MD University of British Columbia, 1961) - further explored the use of various extracranial to intracranial anastomoses for vascular disease, even dementia. In 1985, an international study group effectively dismissed the value of this procedure for ischemic disease, although there can be no doubt of the value in selected instances of cerebral ischemia and planned occlusion of cerebral vessels for vascular or neoplastic disorders. London (Ontario) became an internationally renowned center for neurovascular surgery. Drake's associates, Sidney Peerless and Gary Ferguson, succeeded him as chief of neurosurgery in London. Ferguson remained there. Peerless trained in Toronto with T. Morley and W.M. Lougheed, came to London after a fellowship in Zurich with Yasargil, and later moved to Miami. With Neal Kassell, he was a principal author of a paper ${ }^{46}$ on the largest series of patients treated for vasospasm using volume expansion and induced hypertension. Peerless, working in Vancouver, was reported to have performed the first EC-IC bypass in Western Canada.

After World War II, C. Miller Fisher (1913-2012, born in Waterloo, Ontario, MD Toronto, 1938), began a rotation at the Montreal Neurologic Institute, coming to the attention of Wilder Penfield. Fisher spent 1948 to 1950 as a fellow there, and a year at Boston City Hospital with Raymond Adams. He was the neuropathologist at Montreal General Hospital from 1950 to 1954. He performed more than a thousand autopsies and explored the cervical carotid and intracranial arteries. Arteriography for stroke had been abandoned for a few years in Montreal after serious side effects following use of Thorotrast. ${ }^{47} \mathrm{He}$ subsequently went to Boston and performed another thousand or more autopsies. Fisher's studies led to the recognition of transient monocular blindness (he preferred this term to amaurosis fugax), transient ischemic attacks, embolism from atrial fibrillation to the intracranial vessels as different from occlusion from atherosclerosis-related thrombosis, and cervical carotid occlusion from plaques, and dissection, associated with various cerebrovascular syndromes. He also investigated the role of anticoagulants as treatment as well as the association of hypertension and atherosclerosis in cerebrovascular disease. These studies resulted in banishing so-called "vasospasm" as a cause of these ischemic episodes and its treatment by sympathectomy. In $1951,{ }^{48}$ Fisher stated, "Someday vascular surgery will find a way to bypass the occluded portion of the artery during the period of ominous fleeting symptoms. Anastomosis of the external carotid artery or one of its branches with the internal carotid artery above the area of narrowing should be feasible." He further stated that "the carotid plaque, because of its strictly focal extent, should be amenable to a surgical bypass procedure." On the basis of that article, Carrea et al. ${ }^{49}$ in Buenos Aires performed end-to-end anastomosis of the internal to the external carotid artery in 1951, with a report in 1955 . Fisher also described the "string sign" on cerebral arteriography and the subclavian steal syndrome. In a paper in $1980,{ }^{50}$ he explored the relationship of cerebral vasospasm to the thickness and location of subarachnoid blood on a CT scan, also intraventricular and intraparenchymal blood. The severity of vasospasm and the resulting ischemic deficits correlated with the thickness of subarachnoid blood, and when clots were localized in the region of a given artery with deficits related to the distribution of that artery.

Henry J. M. Barnett (1922-2016), born in Newcastle on Tyne, coincidentally in the same year and town as another neurologist (John Walton, who published a book on subarachnoid hemorrhage and aneurysms), graduated from Toronto in 1944 and trained in Toronto and in England, at Oxford and at Queen's Square, encountering Hugh Cairns in Oxford and Charles Symonds in London. He spent 1952 to 1969 in Toronto. In 1973 he wrote a monograph on syringomyelia, and particularly from trauma, before the advent of MRI. He was closely associated with Drake, first in Toronto and from 1969 in London, Ontario. There, he and Drake worked at Victoria Hospital and in 1969 cofounded the first multidisciplinary neurosciences unit at the University of Western Ontario. He succeeded Drake as chairman of the combined department from 1974 to 1986. Almost a hundred years after Osler's discovery of platelets, his research proved the benefit of aspirin in stroke compared to other antiplatelet agents, especially in males. ${ }^{51}$ In later writings, he indicated that females would also benefit from aspirin. He explored the value of endarterectomy in carotid stenosis ${ }^{52,53}$ based on a consistent classification of stenosis (North American Symptomatic Carotid Endarterectomy Trial). He and neuroradiologist Allan Fox showed that the preventative effects of endarterectomy were apparent for stenosis of $70 \%$ or more, and also in "moderate" stenosis with multiple other risk factors. Symptomatic patients over 75 years of age, with hemispheric symptoms, not just amaurosis, and good collateral circulation were also suitable candidates. Together with Peerless, he wrote on nine patients who developed strokes after uneventful cervical internal carotid occlusion, from turbulent flow in the internal carotid stump releasing emboli into the external carotid and its collaterals feeding the intracranial internal carotid, or perhaps emboli from common carotid or external carotid plaques. ${ }^{54}$ In an international multicentre study, ${ }^{55}$ and in another paper with Fox, Peerless, and V. Hachinski, ${ }^{56}$ they demonstrated the failure of external-to-internal carotid bypass procedures to reduce the risk of ischemic strokes and decrease dementia. Barnett also investigated cerebrovascular accidents from emboli in mitral valve prolapse, and wrote on cerebral venous thrombosis and cranial nerve palsies related to aneurysms. In a paper with Lougheed, ${ }^{57}$ he described "external carotid steal" from the internal or vertebral arteries as causing cerebral ischemic events.

John Allcock (1920-2001) was born in Sheffield, England, and graduated from the Medical School at St. Bartholomew's Hospital in London, England, in 1942. He became a neuroradiologist in London, Ontario, in 1960, retiring in 1978. With Drake, he played a major role in expanding angiography both pre- and postoperatively in order to explore the completeness of aneurysm clipping and, in particular, vasospasm. He is said to have suggested the idea of the (Drake) tourniquet to determine the feasibility of proximal arterial occlusion in aneurysms. Toward the end of his career in London, Ontario, he encouraged endovascular techniques in cerebrovascular disease, and was responsible for recruiting Gerard Debrun (from 1978 to 1981) and Fernando Vinuela (resident and fellow 
1974-1979, then faculty from 1980 to 1986). Both worked extensively in balloon occlusion of aneurysms and fistulae, and in embolizing arteriovenous malformations before moving elsewhere.

Allan J. Fox graduated from McGill in 1970 and joined Allcock in 1976. He played a large role in the indications for operating on carotid occlusion and endovascular treatment of aneurysms. As part of the NASCET study, with Barnett, he defined the degrees of internal carotid stenosis, stratifying which groups were more likely to benefit from endarterectomy. ${ }^{58} \mathrm{He}$ wrote on operating as opposed to stenting and angioplasty for carotid stenosis. He and Barnett described "near occlusion" of the internal carotid and the "string" sign with regard to risk of ischemic events. He also had a prominent role in the IC-EC bypass study.

Arterial vasospasm following subarachnoid hemorrhage has been extensively investigated and written about by Bryce K.A. Weir (1936-, born in Edinburgh, Scotland, MD McGill University, 1960), R. Loch McDonald (MD University of British Columbia, 1985; residency in Toronto, then with Weir in Edmonton), and J. Max Findlay (University of Toronto, trained with A. Hudson, T. Morley, and W.M. Lougheed, and then Weir). Weir trained at the Montreal Neurologic Institute and also in New York. He and his trainees, McDonald and Findlay, have written extensively on the mechanisms of vasospasm. ${ }^{59,60}$ At the University of Alberta, Weir produced a consistent model of subarachnoid hemorrhage in cynomolgus monkeys and evaluated the effects of nimodipine ${ }^{61-64}$ and intracisternal recombinant tissue plasminogen activator (rtPA) to reduce vasospasm by lysis of subarachnoid blood. They investigated numerous substances in cerebrospinal fluid released by hemolysis of erythrocytes and felt that oxyhemoglobin was the most likely spasmogen. ${ }^{63}$ Impairment of cerebrovascular innervation was not thought to play a significant role. ${ }^{65}$ Their histological studies indicated that vasoconstriction seen in vasospasm results in secondary smooth muscle damage, with subsequent migration of smooth muscle cells into the intima, and ultimately their proliferation. They believed that vasospasm abated after radiologic spasm due to longstanding smooth muscle constriction, not vessel wall thickening. In clinical trials, ${ }^{66}$ they found that rtPA did reduce the clinical effects of vasospasm in 19 of 20 patients. There was one case of extradural hemorrhage (probably unrelated), and one patient died from symptomatic vasospasm after failure to adequately lyse the subarachnoid clot. They evaluated the benefits of using tirilazad (a 21-aminosteroid that inhibits lipid peroxidation), which produced better results in the model than in patients. They showed that the removal of subarachnoid clots by lysis or mechanical removal had its best results when utilized within 48 to 72 hours after the bleed. Chemical clot lysis was preferable to mechanically suctioning clots due to the risk of small vessel injury in the latter procedure. They tried the use of intraventricular rtPA. Weir ${ }^{67,68}$ explored the time course of vasospasm related to the bleed. Subsequent papers discussed the role of nimodipine and rtPA in treatment of vasospasm. There was clinical improvement, even if angiographic vasospasm was not reversed or prevented. McDonald et al. ${ }^{69}$ in 2000 analyzed various factors associated with outcome after operation, and concluded that better results were obtained with smaller drops in systolic and mean arterial pressures during the operation compared to preoperative levels in ruptured aneurysms, and a higher intraoperative diastolic pressure in unruptured aneurysms. Younger age and better Hunt/Hess and Fisher scale scores were major factors for better results, but hypothermia did not make much difference. On the other hand, Farrar et al. ${ }^{70}$ from Drake's group induced reduction of mean arterial pressure to $30-40 \mathrm{~mm}$ for brief periods and found this to be well-tolerated. McDonald and colleagues in 2001 reported on the successful use of rtPA and heparin by local infusion to treat thrombosis of the superior and inferior sagittal, straight, and both transverse sinuses, and the vein of Galen and internal cerebral veins by transfemoral catheterization in a 34 -year-old man. ${ }^{71}$ The patient had an uneventful recovery. Interestingly, both Weir and later McDonald were chairmen of neurosurgery at the University of Chicago and Findlay for a short time in London, Ontario, and then Edmonton.

One cannot forget the efforts of neurologists Herbert Hyland and John C. Richardson of Toronto, who were encouraged by McKenzie to investigate subarachnoid hemorrhage and intracranial aneurysms, resulting in a paper in $1941 .{ }^{45}$ Canada's first neuroradiologist, Arthur E. Childe of Montreal and later Winnipeg, encouraged these endeavors. In 1969, W.G. Beattie published a comprehensive review of Canadian contributions to microvascular surgery. ${ }^{72}$

\section{Conclusions}

Canada, with its relatively small population, has been exceptional in the range of its contributions to cerebrovascular neurosurgery: from the autopsy and clinical studies of Osler, Fisher, and Barnett; the "minimal" treatment of vascular disease with aspirin; the unprecedented exploits of the neurosurgeons from loupes to the operating microscope; and then to less invasive endovascular therapies by interventional neuroradiologists collaborating with neurosurgeons. One of the most noteworthy achievements was the binding together of the diverse neuroscience specialties into a combined department in London. It has been a remarkable journey of a hundred years and more.

\section{ACKNOWLEDGEMENTS}

The author would like to acknowledge the support of Dr. Stephen Lownie of Western University, London, Ontario, in reviewing this article, and to thank Tom Cichonski for editorial assistance and Megan Foldenauer for her illustration.

\section{Disclosures}

The authors of this manuscript certify that this manuscript, or any similar manuscript, has not been published previously in whole or in part, and is not under consideration elsewhere. The authors further certify that this manuscript is a unique submission and is not being considered for publication by any other source in any medium.

The author has no conflicts of interest to report, and there were no financial associations with any of the drugs, materials, or devices mentioned in this manuscript.

\section{Statement of Authorship}

As principal author, Dr. Ramnath made all substantial, direct, intellectual contributions to the work, in collaboration with Dr. Lownie.

\section{REFERENCES}

1. Osler W. Aneurisms of the larger cerebral arteries. Can Med Surg J. $1885 ; 14: 660-6$ 
2. Feindel W. Highlights of neurosurgery in Canada. JAMA. 1967;200 (10):853-9.

3. Osler W. On the conditions of the brain suitable for operative interference. Can Pract. 1889;14:165-7.

4. Lougheed WM, Barnett HJ. Lesions producing spontaneous hemorrhage. In Youmans JR ed Neurological Surgery. Philadelphia: Saunders; 1973:709.

5. Osler W. Aneurysm at the second bifurcation of right middle cerebral artery: rupture, extravasation of blood into the Sylvian fissue, laceration of the substance of temporo-sphenoidal lobe: death in 36 hours. Pathol Rep Montreal Gen Hosp. $1876-7 ; 1: 30-2$.

6. Osler W. Transient attacks of aphasia and paralyses in states of high blood pressure and arterio-sclerosis. Can Med Assoc J. 1911;1:919-6.

7. Cooper B. Osler's role in defining the third corpuscle, or "blood plates". Proc Bayl Univ Med Cent. 2005;18(4):376-8.

8. Osler W. Cartwright Lectures. On certain problems in the physiology of the blood corpuscles. Med News. 1886;10(April 3):17.

9. McKenzie KG. Some minor modifications of Harvey Cushing's silver clip outfit. Surg Gynecol Obstet. 1927;45:549-50.

10. Dandy WE. Surgical treatment. In Dandy WE ed Intracranial Arterial Aneurysms. Ithaca, NY: Comstock Publishing; 1944:29.

11. Drake CG. Gordon Murray Lecture. Evolution of intracranial aneurysm surgery. Can J Surg. 1984;27:549-55.

12. Johnson HC. Surgery of cerebral vascular anomalies. In Walker AE ed A History of Neurological Surgery. Baltimore: Williams \& Wilkins; 1951:255-7.

13. Turnbull F. Cerebral angiography by direct injection of the common carotid artery. Am J Roentgen. 1939;41:166-72.

14. Botterell EH, Lougheed WM, Scott JW, Vandewater SL. Hypothermia, and interruption of carotid, or carotid and vertebral circulation, in the surgical management of intracranial aneurysms. J Neurosurg. 1956;13:1-42.

15. Botterell EH, Lougheed WM, Morley TP, Vandewater SL. Hypothermia in the surgical treatment of ruptured intracranial aneurysms. J Neurosurg. 1958;15:4-18.

16. Findlay JM. William M. Lougheed and the development of vascular neurosurgery at the Toronto General Hospital. Can J Neurol Sci. 1993;20:337-40.

17. Lougheed WM, Kahn DS. Circumvention of anoxia during arrest of cerebral circulation for intracranial surgery. J Neurosurg. 1955;12:226-39.

18. Lougheed WM, Sweet WH, White JC, Brewster WR. The use of hypothermia in surgical treatment of cerebral vascular lesions: a preliminary report. J Neurosurg. 1955;12:240-55.

19. Hamlin H, Sweet WH, Lougheed WM. Surgical reconstruction of occluded cervical carotid artery: report of a successful case with 4-year follow up and three examples without such treatment. J Neurosurg. 1958;15:427-37.

20. Lougheed WM, Tom M. A method of introducing blood into the subarachnoid space in the region of the circle of Willis in dogs. Can J Surg. 1961;4:329-37.

21. Lougheed WM, Marshall BM. The diploscope in intracranial aneurysm surgery: results in 40 patients. Can J Surg. 1969;12: 75-82.

22. Khodadad G, Lougheed WM. Repair of small arteries with contact cement and Teflon graft. J Neurosurg. 1964;21:552-60.

23. Khodadad G, Lougheed WM. Stapling technique in segmental vein autografts and end-to-end anastomosis of small vessels in dogs: utilization of the operating microscope. J Neurosurg. 1966; 24:855-64.

24. Khodadad G, Lougheed WM. Repair and replacement of small arteries, microsuture technique. J Neurosurg. 1966;24:61-9.

25. Gentili F, Lougheed WM, Yoshijima S, Hondo H, MacKay MB. A technique for rapid non-suture vascular anastomosis. Can J Neurol Sci. 1987;14:92-5.

26. Jacobson JH 2nd, Wallman LJ, Schumacher GA, Flanagan M, Suarez EL, Donaghy RM. Microsurgery as an aid to middle cerebral artery endarterectomy. J Neurosurg. 1962;19: 108-115.

27. Chou SN. Embolectomy of middle cerebral artery: report of a case. J Neurosurg. 1963;20:161-3.
28. Scheibert CD. Middle cerebral artery surgery for obstructive lesions. Paper presented at the 27th Annual Meeting of the Harvey Cushing Society; New Orleans, LA; May 1959.

29. Lougheed WM, Gunton RW, Barnett HJ. Embolectomy of internal carotid, middle and anterior cerebral arteries. Report of a case. J Neurosurg. 1965;22:607-9.

30. Lougheed WM, Marshall BM, Hunter M, Michel ER, SandwithSmyth H. Common carotid to intracranial internal carotid bypass venous graft: technical note. J Neurosurg. 1971;34:114-8.

31. Lougheed WM, Khodadad G. A new clip for surgery of the intracranial and small blood vessels. J Neurosurg. 1965;22:397-8.

32. Parkinson D. Collateral circulation of cavernous carotid artery: anatomy. Can J Surg. 1964;7:251-68.

33. Parkinson D. A surgical approach to the cavernous portion of the carotid artery: anatomical studies and case report. J Neurosurg. 1965;23:474-83.

34. Parkinson D, MacPherson RA, Childe AE, Middlecote LR, Morrow IM, MacEwan DW. Routine simultaneous bi-plane stereoscopic angiography. J Can Assoc Radiol. 1967;18:371-6.

35. Parkinson D. Cerebral arteriovenous aneurysms: surgical management. Can J Surg. 1958;1:313-25.

36. Yasargil MG. The history of optical instruments in microsurgery. In Barrow DL, Kondziolka D, Laws ER, Traynelis VG eds Fifty Years of Neurosurgery. Lippincott Williams and Wilkins; 2000:113.

37. Drake CG. Bleeding aneurysms of the basilar artery: direct surgical management in four cases. J Neurosurg. 1961;18:230-8.

38. Drake CG. Giant intracranial aneurysms: experience with surgical treatment in 174 patients. Clin Neurosurg. 1979;26: 12-95.

39. Del Maestro RF. Origin of the Drake fenestrated aneurysm clip. J Neurosurg. 2000;92:1056-64.

40. Drake CG, Hunt WE, Kassell N, et al. Report of the World Federation of Neurological Surgeons Committee on a Universal Subarachnoid Hemorrhage Grading Scale. J Neurosurg. 1988;68: 985-6.

41. Drake CG, Barr HW, Coles JC, Gergely NF. The use of extracorporeal circulation and profound hypothermia in the treatment of ruptured intracranial aneurysm. J Neurosurg. 1964; 21:575-81.

42. Allcock JM, Drake CG. Postoperative angiography in cases of ruptured intracranial aneurysm. J Neurosurg. 1963;20:752-9.

43. Allcock JM, Drake CG. Ruptured intracranial aneurysms: the role of arterial spasm. J Neurosurg. 1965;22:21-9.

44. Ecker A, Riemenschneider PA. Arteriographic demonstration of spasm of the intracranial arteries, with special reference to saccular arterial aneurysms. J Neurosurg. 1951;8:660-7.

45. Richardson JC, Hyland HH. A clinical and pathological study of subarachnoid and intracerebral haemorrhage caused berry aneurysms. Medicine. 1941;20:1-84.

46. Kassell NF, Peerless SJ, Durward QJ, Beck DW, Drake CG, Adams HP. Treatment of ischemic deficits from vasospasm with intravascular volume expansion and induced arterial hypertension. Neurosurgery. 1982;11:337-43.

47. Estol CJ. Dr C. Miller Fisher and the history of carotid artery disease. Stroke. 1996;27:559-66.

48. Fisher M. Occlusion of the internal carotid artery. AMA Arch Neurol Psychiatry. 1951;65:346-77.

49. Carrea R, Molins M, Murphy G. Surgery of spontaneous thrombosis of the internal carotid in the neck; carotido-carotid anastomosis; case report and analysis of the literature on surgical cases [in Spanish]. Medicina (B Aires). 1955;15:20-9.

50. Fisher CM, Kistler JP, Davis JM. Relation of cerebral vasospasm to subarachnoid hemorrhage visualized by computerized tomographic scanning. Neurosurgery. 1980;6:1-9.

51. Canadian Cooperative Study Group. A randomized trial of aspirin and sulfinpyrazone in threatened stroke. N Engl J Med. 1978; 299:53-9.

52. Morgenstern LB, Fox AJ, Sharpe BL, Eliasziw M, Barnett HJ, Grotta JC. The risks and benefits of carotid endarterectomy in patients with near occlusion of the carotid artery. North American Symptomatic Carotid Endarterectomy Trial (NASCET) Group. Neurology. 1997;48:911-5. 
53. North American Symptomatic Carotid Endarterectomy Trial Collaborators, HJM Barnett, Taylor DW, et al. Beneficial effect of carotid endarterectomy in symptomatic patients with high-grade carotid stenosis. N Engl J Med. 1991;325:445-53.

54. Barnett HJ, Peerless SJ, Kaufmann JC. "Stump" on internal carotid artery: a source for further cerebral embolic ischemia. Stroke. 1978;9:448-56.

55. EC/IC Bypass Study Group. Failure of extracranial-intracranial arterial bypass to reduce the risk of ischemic stroke. Results of an international randomized trial. N Engl J Med. 1985;313: 1191-200.

56. Barnett HJ, Fox A, Hachinski V, et al. Further conclusions from the extracranial-intracranial bypass trial. Surg Neurol. 1986;26: 227-235.

57. Barnett HJ, Wortzman G, Gladstone RM, Lougheed WM. Diversion and reversal of cerebral blood flow: external carotid artery "steal". Neurology. 1970;20:1-14.

58. Fox AJ. How to measure carotid stenosis. Radiology. 1993;186: 316-318.

59. Macdonald RL, Weir B. Cerebral Vasospasm. San Diego: Academic Press; 2001.

60. Weir B. Subarachnoid Hemorrhage: Causes and Cures. New York. Oxford University Press; 1998.

61. Espinosa F, Weir B, Boisvert D, Overton T, Castor W. Chronic cerebral vasospasm after large subarachnoid hemorrhage in monkeys. J Neurosurg. 1982;57:224-32.

62. Espinosa F, Weir B, Overton T, Castor W, Grace M, Boisvert D. A randomized placebo-controlled double-blind trial of nimodipine after SAH in monkeys, part 1: clinical and radiological findings. J Neurosurg. 1984;60:1167-75.
63. Espinosa F, Weir B, Shnitka T, Overton T, Boisvert D. A randomized placebo-controlled double-blind trial of nimodipine after SAH in monkeys, part 2: pathological findings. J Neurosurg. 1984; 60:1176-85.

64. Weir BK. Cerebral vasospasm: experimental study [in French]. Neurochirurgie. 1992;38:129-33.

65. Macdonald RL, Weir BK. Management of vasospasm: tissue plasminogen activator. In Ratcheson RA, Wirth FP eds Ruptured Cerebral Aneurysms: Perioperative Treatment. Baltimore: Williams \& Wilkins; 1994:168-81.

66. Findlay JM, Macdonald RL, Weir BK. Current concepts of pathophysiology and management of cerebral vasospasm following aneurysmal subarachnoid hemorrhage. Cerebrovasc Brain Metab Rev. 1991;3:336-61.

67. Weir B. The pathophysiology of cerebral vasospasm. $\mathrm{Br} \mathrm{J}$ Neurosurg. 1995;9:375-90.

68. Weir B, Grace M, Hansen J, Rothberg C. Time course of vasospasm in man. J Neurosurg. 1978;48:173-8.

69. Foroohar M, Macdonald RL, Roth S, Stoodley M, Weir B. Intraoperative variables and early outcome after aneurysm surgery. Surg Neurol. 2000;54:304-15.

70. Farrar JK, Gamache FW Jr., Ferguson GG, Barker J, Varkey GP, Drake CG. Effects of profound hypotension on cerebral blood flow during surgery for intracranial aneurysms. J Neurosurg. 1981;55:857-64.

71. Yamini B, Loch Macdonald R, Rosenblum J. Treatment of deep cerebral venous thrombosis by local infusion of tissue plasminogen activator. Surg Neurol. 2001;55:340-6.

72. Beattie WG. Canadian contributions to microvascular surgery. Can J Surg. 1969;12(1):129-35. 